\section{$\underset{\substack{\text { hommes } \\ \text { \& migrations }}}{ }$}

\section{Hommes \& migrations}

Revue française de référence sur les dynamiques

migratoires

$1297 \mid 2012$

Migrations en création

\title{
Migrations et récits en Europe
}

\section{Odile Chenal}

\section{QpenEdition \\ Journals}

\section{Édition électronique}

URL : http://journals.openedition.org/hommesmigrations/1315

DOI : 10.4000/hommesmigrations.1315

ISSN : 2262-3353

\section{Éditeur}

Musée national de l'histoire de l'immigration

\section{Édition imprimée}

Date de publication : 1 mai 2012

Pagination : 128

ISSN : 1142-852X

\section{Référence électronique}

Odile Chenal, « Migrations et récits en Europe », Hommes \& migrations [En ligne], 1297 | 2012, mis en

ligne le 29 mai 2013, consulté le 22 septembre 2020. URL : http://journals.openedition.org/

hommesmigrations/1315; DOI : https://doi.org/10.4000/hommesmigrations.1315

Ce document a été généré automatiquement le 22 septembre 2020.

Tous droits réservés 
Migrations et récits en Europe

Odile Chenal 
1 La Fondation européenne de la culture (FEC) a lancé en 2010 une série de séminaires sur le thème "Narratives for Europe". Pour une troisième rencontre, elle s'est associée à la Cité nationale de l'histoire de l'immigration afin de débattre de la production et de la présentation dans les institutions patrimoniales des "récits sur l'Europe". Une attention particulière a été donnée aux migrants, ces Européen(ne)s qui ont aussi une partie de leur vie ou de leur histoire sur d'autres continents.

2 Le débat a tenu compte de la complexité du concept de narratives en donnant la parole aux chercheurs/écrivains/ artistes autour des questions suivantes :

- L'Europe a-t-elle une place dans les récits des migrants? Peut-on parler d'expériences ou de visions spécifiques de l'Europe et de l'Union européenne ? Y a-t-il une spécificité du sens de l'appartenance - ou de la non appartenance - à l'espace culturel européen ?

- Quel rôle jouent les artistes : transmetteurs, amplificateurs, révélateurs de ces récits?

-Quelle place pour la population, qu'elle soit ou non migrante, lorsqu'on l'incite à s'exprimer sur son sentiment d'appartenance à l'Europe ?

- En quoi les créations construites à partir de récits ou de narratives contribuent-elles à écrire l'histoire de ce destin commun en Europe, à la fois voulu et contesté ?

3 Cette rencontre a réuni un public divers de professionnels (artistes, acteurs culturels, chercheurs, associations, institutions) et s'est organisée en trois temps afin que la complexité des approches puisse être prise en compte.

- Visite-conférence de l'exposition J'ai deux amours présentée par Isabelle Renard, commissaire de l'exposition.

- Réflexion sur les notions de récits et de citoyenneté européenne ainsi que sur le rôle des institutions patrimoniales.

- Présentation par les artistes et par une association de leurs démarches artistiques et de leurs projets culturels.

4 Ce séminaire s'est tenu en parallèle avec l'exposition J'ai deux amours qui a présenté les collections d'art contemporain du Musée d'histoire et des cultures de l'immigration à la Cité nationale de l'histoire de l'immigration du 16 novembre 2011 au 24 juin 2012.

\section{AUTEUR}

ODILE CHENAL

Chargée de recherche et développement, European Cultural Foundation 